\title{
Association of $\beta$-Amyloid Level, Clinical Progression, and Longitudinal Cognitive Change in Normal Older Individuals
}

\author{
Laura M. van der Kall, MSc, Thanh Truong, BH-BMed, Samantha C. Burnham, PhD, Vincent Doré, PhD, \\ Rachel S. Mulligan, PhD, Svetlana Bozinovski, RN, Fiona Lamb, DPsych, Pierrick Bourgeat, PhD, \\ Jurgen Fripp, PhD, Stephanie Schultz, MSc, Yen Y. Lim, PhD, Simon M. Laws, PhD, David Ames, MD, \\ Christopher Fowler, PhD, Stephanie R. Rainey-Smith, PhD, Ralph N. Martins, PhD, Olivier Salvado, PhD, \\ Joanne Robertson, DPsych, Paul Maruff, PhD, Colin L. Masters, MD, Victor L. Villemagne, MD, and \\ Christopher C. Rowe, MD
}

Neurology ${ }^{\circledR}$ 2021;96:e662-e670. doi:10.1212/WNL.0000000000011222

\author{
Correspondence \\ Dr. Rowe \\ christopher.rowe@austin.org.au
}

\begin{abstract}
Objective

To determine the effect of $\beta$-amyloid (A $\beta$ ) level on progression risk to mild cognitive impairment $(\mathrm{MCI})$ or dementia and longitudinal cognitive change in cognitively normal $(\mathrm{CN})$ older individuals.

\section{Methods}

All CN from the Australian Imaging Biomarkers and Lifestyle study with A $\beta$ PET and $\geq 3$ years follow-up were included ( $n=534$; age $72 \pm 6$ years; $27 \% \mathrm{~A} \beta$ positive; follow-up $5.3 \pm 1.7$ years). A $\beta$ level was divided using the standardized $0-100$ Centiloid scale: $<15$ CL negative, 15-25 CL uncertain, 26-50 CL moderate, 51-100 CL high, >100 CL very high, noting >25 CL approximates a positive scan. Cox proportional hazards analysis and linear mixed effect models were used to assess risk of progression and cognitive decline.
\end{abstract}

\section{Results}

$\mathrm{A} \beta$ levels in $63 \%$ were negative, $10 \%$ uncertain, $10 \%$ moderate, $14 \%$ high, and $3 \%$ very high. Fifty-seven (11\%) progressed to MCI or dementia. Compared to negative $\mathrm{A} \beta$, the hazard ratio for progression for moderate $\mathrm{A} \beta$ was 3.2 (95\% confidence interval $[\mathrm{CI}] 1.3-7.6 ; p<0.05$ ), for high was 7.0 (95\% CI 3.7-13.3; $p<0.001$ ), and for very high was 11.4 (95\% CI 5.1-25.8; $p<$ $0.001)$. Decline in cognitive composite score was minimal in the moderate group $(-0.02 \mathrm{SD} /$ year, $p=0.05$ ), while the high and very high declined substantially (high $-0.08 \mathrm{SD} /$ year, $p<$ 0.001 ; very high $-0.35 \mathrm{SD} /$ year, $p<0.001$ ).

\section{Conclusion}

The risk of MCI or dementia over 5 years in older $\mathrm{CN}$ is related to A $\beta$ level on PET, $5 \%$ if negative vs $25 \%$ if positive but ranging from $12 \%$ if $26-50$ CL to $28 \%$ if $51-100 \mathrm{CL}$ and $50 \%$ if $>100 \mathrm{CL}$. This information may be useful for dementia risk counseling and aid design of preclinical $\mathrm{AD}$ trials. 


\section{Glossary}

$\mathbf{A} \beta=\beta$-amyloid $; \mathrm{AD}=$ Alzheimer disease $; \mathrm{ADNI}=$ Alzheimer's Disease Neuroimaging Initiative $\mathbf{A I B L}=$ Australian Imaging, Biomarkers and Lifestyle; CDR-SoB = Clinical Dementia Rating Sum of Boxes; $\mathbf{C L}=$ Centiloid; $\mathbf{C N}=$ cognitively normal; CVLT-II LDFR = California Verbal Learning Test II long delay free recall; HA = hippocampal atrophy; HR = hazard ratio; $\mathbf{H V}=$ hippocampal volume; $\mathbf{M C I}=$ mild cognitive impairment $\mathbf{P A C C}=$ Preclinical AD Cognitive Composite $\mathbf{P I}=$ post-tracer injection; PiB = Pittsburgh compound B; SUVR = standardized uptake value ratio.

$\beta$-amyloid $(A \beta)$ deposition begins decades prior to dementia due to Alzheimer disease $(\mathrm{AD})$ and is an important predictor of mild cognitive impairment (MCI) or dementia in cognitively normal $(\mathrm{CN})$ individuals. ${ }^{1-3}$ Preventative treatments should target this early stage of the disease ${ }^{4-10}$ and identifying those at highest risk of decline would allow faster clinical trials.

In most current clinical practice and research settings, A $\beta$ PET scans are classified as positive or negative, but limited data suggest that the risk of progression is related to the level of $A \beta$ in individuals with a positive scan. ${ }^{10,11}$

The Centiloid (CL) scale was developed to standardize $A \beta$ imaging measures ${ }^{12-15}$ and to aid the adoption of widely applicable thresholds for PET A $\beta$ levels that correspond with histopathologic classification ${ }^{16-18}$ and correlate with prognosis. Zero CL corresponds to the mean scan measure of healthy young adults without $A \beta$ deposition and $100 \mathrm{CL}$ corresponds to the mean scan measure of patients with mild $\mathrm{AD}$ dementia. Twenty-five CL corresponds approximately with the discrimination between a positive vs a negative scan by an expert visual reader, and with most standardized uptake value ratio (SUVR) thresholds. ${ }^{19}$

The objective of this study was to determine the effect of $A \beta$ level expressed in $\mathrm{CL}$ on the progression risk to $\mathrm{MCI}$ or dementia in $\mathrm{CN}$ individuals. We further examined associations between $A \beta$ burden and longitudinal change in cognition.

\section{Methods}

\section{Participants}

A total of $534 \mathrm{CN}$ individuals from the Australian Imaging, Biomarkers and Lifestyle (AIBL) study with at least 3 years of clinical follow-up after an A $\beta$ PET scan were identified. They underwent a screening visit consisting of a clinical and neuropsychological assessment, $A P O E$ genotyping, and $\mathrm{A} \beta \mathrm{PET}$ and MRI scans. ${ }^{20}$ Participants were followed longitudinally at approximately 18 -month intervals. After each visit, a clinical panel reviewed the neuropsychological information of the participants blinded to all imaging findings and the participants were classified as $\mathrm{CN}$ or were diagnosed with $\mathrm{MCI}, \mathrm{AD}$, or other dementia. Diagnosis was based on standard clinical criteria for $\mathrm{MCI}^{21}$ and $\mathrm{AD} .{ }^{22}$ Participants diagnosed with MCI or any type of dementia during the follow-up period were classified as progressors and participants not meeting any criteria for MCI or dementia were classified as clinically stable.
Genotyping of $A P O E$ was determined by direct sequencing at baseline. Participants with at least 1 APOE $\varepsilon 4$ allele were classified as $A P O E \varepsilon 4$ carriers.

\section{Standard Protocol Approvals, Registrations, and Patient Consents}

Written informed consent was obtained from all participants. Data from the AIBL study was used and a detailed description of the AIBL methods can be found elsewhere. ${ }^{20}$ The AIBL study was approved by the ethics committee of St Vincent's Health, Austin Health, Hollywood Private Hospital, and Edith Cowan University.

\section{Neuropsychological Evaluation}

All participants received the AIBL neuropsychological test battery as previously described in detail. ${ }^{20}$

To assess cognitive performance longitudinally, 3 measures were used: Clinical Dementia Rating Sum of Boxes (CDRSoB), California Verbal Learning Test II long delay free recall (CVLT-II LDFR), and a cognitive composite score called the AIBL-Preclinical AD Cognitive Composite (PACC). The AIBL-PACC is based on the ADCS-PACC derived by Donohue et al. ${ }^{23}$ and has been shown to be sensitive for deterioration in cognition in clinically normal older cohorts. The AIBL-PACC consists of the Mini-Mental State Examination, Digit Symbol Substitution Test from the Wechsler Adult Intelligence Scale, CVLT-II LDFR, and Logical Memory IIa subtest from the Wechsler Memory Scale. For each individual, the $Z$ scores of each of the 4 test scores were mean averaged to give a PACC $Z$ score.

\section{Imaging Methods and Analysis}

$\mathrm{A} \beta$ PET imaging was conducted using $\mathrm{A} \beta$ tracers: ${ }^{11} \mathrm{C}-\mathrm{Pittsburgh}$ compound $\mathrm{B}(\mathrm{PiB}),{ }^{18} \mathrm{~F}$-florbetapir, or ${ }^{18} \mathrm{~F}$-flutemetamol. As described previously, PET acquisitions were performed 40-70 minutes post-tracer injection (PI) for ${ }^{11} \mathrm{C}$-PiB, 50-70 minutes PI for ${ }^{18} \mathrm{~F}$-florbetapir, and $90-110$ minutes PI for ${ }^{18} \mathrm{~F}$-flutemetamol. PET images were not corrected for partial volume correction. All $A \beta$ PET scans were quantified using CapAIBL ${ }^{24}$ and the $A \beta$ level was expressed in CLs as described by Klunk et al. ${ }^{12}$ and Bourgeat et al. ${ }^{25} \mathrm{~A} \beta$ level was classified according to 5 categories: $<15 \mathrm{CL}$ negative, 15-25 CL uncertain, 26-50 CL moderate, 51-100 CL high, $>100 \mathrm{CL}$ very high. The category limits were chosen prior to data analysis based on published CL information. Notably, studies reporting CL findings in younger controls aged under 45 years give an average of $11 \mathrm{CL}$ as the $2 \mathrm{SD}$ upper limit above the mean of $0 \mathrm{CL}$, while postmortem correlation studies indicate 
Table 1 Participant Characteristics

\begin{tabular}{|c|c|c|c|}
\hline & All $(n=534)$ & Progressors $(n=57)$ & Clinically stable $(n=477)$ \\
\hline Age, y & $72 \pm 6(56-90)$ & $74 \pm 6(62-88)$ & $72 \pm 6(56-90)^{a}$ \\
\hline Female & $295(55)$ & $27(47)$ & $268(56)$ \\
\hline Education, y & $13 \pm 3(6-22)$ & $13 \pm 3(6-22)$ & $13 \pm 3(6-22)$ \\
\hline Tested for $A P O E \varepsilon 4$ & All $(n=504)$ & Progressors $(n=55)$ & Clinically stable $(n=449)$ \\
\hline$A P O E \& 4$ carrier & $140(28)$ & $30(55)$ & $110(24)^{b}$ \\
\hline Tested for memory impairment & All $(n=533)$ & Progressors $(n=57)$ & Clinically stable $(n=476)$ \\
\hline Memory impairment ${ }^{d}$ & $81(15)$ & $22(39)$ & $59(12)^{b}$ \\
\hline Tested for hippocampal atrophy & All $(n=442)$ & Progressors $(n=48)$ & Clinically stable $(n=394)$ \\
\hline Hippocampal atrophy & $88(20)$ & $19(40)$ & $69(18)^{b}$ \\
\hline \multicolumn{4}{|l|}{$\beta$-amyloid level } \\
\hline Negative & $337(63)$ & $17(30)$ & $320(67)^{c}$ \\
\hline Uncertain & $52(10)$ & $4(7)$ & $48(11)$ \\
\hline Moderate & $51(10)$ & $6(11)$ & $45(9)$ \\
\hline High & $76(14)$ & $21(37)$ & $55(12)^{c}$ \\
\hline Very high & $18(3)$ & $9(16)$ & $9(2)^{c}$ \\
\hline Time to progression, $y$ & & $3.6 \pm 1.8(1.4-7.6)$ & \\
\hline Length of follow-up, $y$ & $5.3 \pm 1.7(2.7-8.0)$ & $5.0 \pm 1.7(2.8-8.0)$ & $5.4 \pm 1.7(2.7-8.0)$ \\
\hline
\end{tabular}

Data are presented as mean \pm SD (range) or $n$ (\% of column total).

Differences between progressors and cognitively stable participants were assessed using aindependent $t$ test $p<0.05,{ }^{b}$ Pearson $\chi^{2}$ test $p<0.01,{ }^{C}$ Fisher exact test $p<0.01$

${ }^{d}$ Defined by California Verbal Test II delayed free recall $Z$ score as $\leq-1.0$.

Consortium to Establish a Registry for Alzheimer's Disease (CERAD)-classified moderate neuritic plaque density may be found at $15 \mathrm{CL}$ but usually is associated with $>25 \mathrm{CL} .^{12-18}$ Consequently, we set $<15 \mathrm{CL}$ as negative, $15-25$ as uncertain, and then, to reflect categories that may be useful to a clinician for determining individual prognosis, divided the traditionally positive scans into the 3 categories of moderate, high, and very high.

3T MRI 3D magnetization-prepared rapid gradient echo was used to measure hippocampal volume (HV) corrected for whole brain volume. ${ }^{26}$ Using the $\mathrm{HV}$ of the AIBL CN and AD groups, the Youden Index was applied to determine optimal $\mathrm{HV}$ cutoff value for hippocampal atrophy (HA), yielding HA $\leq 2.74 \mathrm{~cm}^{3}$ for sensitivity $85 \%$, specificity $86 \%$.

\section{Statistical Analyses}

Statistical analyses were performed using RStudio, version 3.5.3, with statistical significance at $p<0.05$. Differences between the progressors and the clinically stable group were assessed with independent $t$ test for continuous data (age, years of education, and length of follow-up), $\chi^{2}$ testing for categorical data (sex, $A P O E \& 4$ status, and HA), and Fisher exact test (A $\beta$ categories).

Cox proportional hazards analysis was used to examine the effect of the $A \beta$ levels and other measures (age, sex, years of education, $A P O E \& 4$ status, low baseline memory performance, and HA) on clinical progression to MCI or dementia. The visit with the first PET scan was identified as the baseline visit and the event was classified as the progression to MCI or dementia. Survival was defined as the time between baseline and the event, or withdrawal, or the last available follow-up examination. We also analyzed the data truncated at the 4.5year follow-up due to concern about the relatively small number of at risk $\mathrm{A} \beta$-positive individuals beyond this point.

For this analysis, age and years of education were dichotomized by using a cutoff value of 72 years for age and $\leq 13$ years for education (mean of this CN cohort). CVLT-II LDFR was used to classify $\mathrm{CN}$ participants as low memory performance at baseline when the $Z$ score was $\leq-1.0$ using the mean and SD of the $\mathrm{CN}$ cohort with no correction for age but they did not meet criteria for MCI. Hazard ratios (HRs) were calculated to examine the effect of the factors on progression.

Linear mixed effects models were performed to examine the association between $A \beta$ level and the longitudinal change in cognitive performance. Three models were created for the following variables: AIBL-PACC, CVLT-II LDFR, CDR-SoB. Time from baseline (years), $A \beta$ level, and their interaction were included as fixed effects. Participant identification 
Table 2 Characteristics of Participants Based on Centiloid Group

\begin{tabular}{|c|c|c|c|c|c|c|c|}
\hline & \multicolumn{2}{|c|}{ Negative $(n=337)$} & \multicolumn{2}{|c|}{ Uncertain $(n=52)$} & Moderate $(n=51)$ & High $(n=76)$ & Very high $(n=18)$ \\
\hline Age, y & \multicolumn{2}{|l|}{$71 \pm 6$} & \multicolumn{2}{|c|}{$72 \pm 4$} & $75 \pm 6^{\mathrm{a}, \mathrm{b}}$ & $74 \pm 6^{a, b}$ & $76 \pm 6^{a, b}$ \\
\hline Female & \multicolumn{2}{|c|}{$191(57)$} & \multicolumn{2}{|c|}{$25(48)$} & $26(51)$ & $44(58)$ & $9(50)$ \\
\hline Education, y & \multicolumn{2}{|l|}{$13 \pm 3$} & \multicolumn{2}{|c|}{$12 \pm 3$} & $12 \pm 3$ & $13 \pm 3$ & $13 \pm 3$ \\
\hline Tested for memory & \multicolumn{2}{|c|}{ Negative $(n=336)$} & \multicolumn{2}{|c|}{ Uncertain $(n=52)$} & Moderate $(n=51)$ & High $(n=76)$ & Very high $(n=18)$ \\
\hline Memory impairment ${ }^{f}$ & \multicolumn{2}{|c|}{$43(13)$} & \multicolumn{2}{|c|}{$9(17)$} & $13(25)^{c}$ & $12(16)$ & $4(22)$ \\
\hline AIBL-PACC & \multicolumn{2}{|c|}{$0.21 \pm 0.83$} & \multicolumn{2}{|c|}{$0.28 \pm 0.78$} & $0.04 \pm 1.02$ & $-0.15 \pm 0.92^{\mathrm{a}}$ & $0.27 \pm 1.07$ \\
\hline Tested for $A P O E \varepsilon 4$ & \multicolumn{2}{|c|}{ Negative $(n=315)$} & \multicolumn{2}{|c|}{ Uncertain $(n=48)$} & Moderate $(n=50)$ & High $(n=74)$ & Very high $(n=17)$ \\
\hline$A P O E \& 4$ carrier & \multicolumn{2}{|c|}{$60(19)$} & \multicolumn{2}{|c|}{$10(21)$} & $23(46)^{c, d}$ & $35(47)^{c, d}$ & $12(71)^{\mathrm{d}, \mathrm{e}}$ \\
\hline \multicolumn{2}{|c|}{ Tested hippocampal volume } & \multicolumn{2}{|c|}{ Negative $(n=277)$} & Uncertain $(n=42)$ & Moderate $(n=43)$ & High $(n=65)$ & Very high $(n=15)$ \\
\hline Hippocampal atrophy & & $43(16)$ & & $10(24)$ & $11(26)$ & $18(28)^{c}$ & $6(40)^{\mathrm{e}}$ \\
\hline
\end{tabular}

Abbreviations: AIBL-PACC $=$ Preclinical AD Cognitive Composite

Data are presented as mean \pm SD or $n$ (\% of column total).

Statistical differences $(p<0.05)$ between Centiloid groups were assessed using aindependent $t$ test compared to negative, bindependent $t$ test compared to uncertain, ${ }^{C}$ Pearson $\chi^{2}$ test compared to negative, ${ }^{\mathrm{C}}$ Pearson $\chi^{2}$ test compared to uncertain, ${ }^{\mathrm{e}}$ Fisher exact test compared to negative. No other comparisons were significant.

${ }^{\mathrm{f}}$ Defined by California Verbal Test II delayed free recall $Z$ score as $\leq-1.0$.

number (intercept) and time from baseline (slope) were included as random factors. Sex, age, years of education, and $A P O E \& 4$ status were included as covariates. Data from 5 review cycles, approximately equivalent to baseline and 18 months, 36 months, 54 months, and 72 months follow-up, were included in each of the models.

\section{Data Availability}

Most baseline data are available on the AIBL subsection of the adni.loni.usc.edu website. Limited follow-up data are available at this site and access to all the data in this article can be requested through an application to the AIBL management committee.

\section{Results}

\section{Baseline Findings}

Demographic characteristics of the $534 \mathrm{CN}$ participants are shown in tables 1 and 2 . At baseline, the mean age was $72 \pm 6$ years, $55 \%$ were women, $28 \%$ were APOE $\varepsilon 4$ positive, and $27 \%$ were $A \beta$ scan positive using a threshold of $25 \mathrm{CL}$. During the follow-up period of $5.3 \pm 1.7$ years, 57 participants (11\%) progressed to $\mathrm{MCI}$ or dementia.

Age, APOE $\varepsilon 4$ status, baseline CVLT-II LDFR, and HA were significantly different between the progressors and clinically stable group (table 1$)$. A $\beta$ level ( $>50 \mathrm{CL}$ ) was more prevalent in the progressor group while $A \beta$ level $(<15 \mathrm{CL})$ was more prevalent in the stable group. HA was more prevalent in the progressor group (table 1).

Table 2 shows that the groups with greater $A \beta$ burden were older and had a higher prevalence of $A P O E \varepsilon 4$ and HA than the $\mathrm{A} \beta$-negative group.

\section{$A \beta$ and Clinical Progression}

We assessed the effect of the individual factors on clinical progression to MCI or dementia (table 3). By the 4.5-year follow-up time point, 79 (15\%) of the stable participants had withdrawn. Their baseline demographics were no different from the whole cohort. In particular, the proportion in each CL

Table 3 Univariate Cox Regression Hazard Ratio (95\% Confidence Interval)

\begin{tabular}{|c|c|c|}
\hline & \multicolumn{2}{|l|}{ All $\mathrm{MCl}$ or $\mathrm{AD}$} \\
\hline & $4.5 \mathrm{y}$ & Full Data Set \\
\hline Age & $1.2(0.6-2.2)$ & $1.8(1.1-3.1)^{b}$ \\
\hline Male & $1.6(0.9-3.0)$ & $1.4(0.8-2.3)$ \\
\hline Lower education & $1.1(0.6-2.0)$ & $0.9(0.5-1.5)$ \\
\hline CVLT-II LDFR & $1.8(0.8-3.7)$ & $4.0(2.4-6.8)^{a}$ \\
\hline$A P O E \varepsilon 4$ & $3.3(1.7-6.2)^{a}$ & $3.3(1.9-5.6)^{a}$ \\
\hline Hippocampal atrophy & $3.1(1.6-6.1)^{a}$ & $1.8(1.0-3.1)^{b}$ \\
\hline \multicolumn{3}{|l|}{$A \beta$ level } \\
\hline Uncertain & $1.3(0.4-4.3)$ & $1.6(0.5-4.7)$ \\
\hline Moderate & $0.9(0.2-4.0)$ & $3.2(1.3-7.6)^{b}$ \\
\hline High & $5.2(2.5-10.5)^{a}$ & $7.0(3.7-13.3)^{a}$ \\
\hline Very high & $8.1(3.1-20.8)^{a}$ & $11.4(5.1-25.8)^{c}$ \\
\hline
\end{tabular}

Abbreviations: $\mathrm{MCI}$ or AD CVLT-II LDFR A $\beta$

Data are hazard ratio (95\% confidence interval) from univariate Cox regression fitted to each column where ${ }^{\mathrm{a}}$ is $p<0.001,{ }^{\mathrm{b}}$ is $p<0.05$, age is $>72$ years, lower education is $<13$ years, CVLT is $<-1.0 \mathrm{SD}$, and hippocampal atrophy is $\leq 2.74 \mathrm{~cm}^{3}$. 


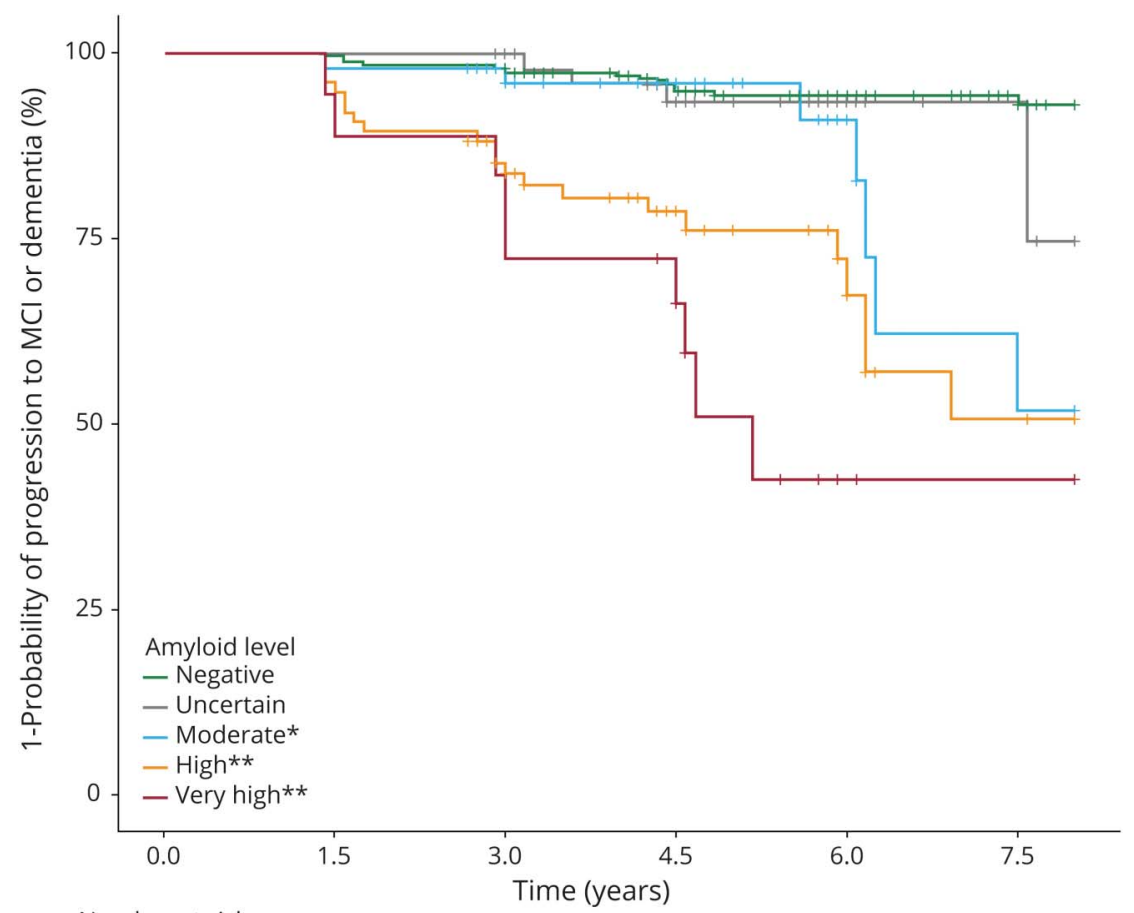

Number at risk:

\begin{tabular}{|c|c|c|c|c|c|c|}
\hline$=$ & 337 & 337 & 331 & 277 & 161 & 91 \\
\hline$=$ & 52 & 52 & 52 & 44 & 26 & 5 \\
\hline$=$ & 51 & 51 & 50 & 41 & 20 & 6 \\
\hline$=$ & 76 & 76 & 68 & 48 & 24 & 9 \\
\hline$=$ & 18 & 18 & 16 & 13 & 5 & 1 \\
\hline
\end{tabular}

An event was defined as progression to mild cog nitive impairment $(\mathrm{MCl})$ or dementia. Number at risk refers to those assessed at each time point who had not progressed. category was no different (64\% negative, $8 \%$ uncertain, 10\% moderate, $18 \%$ high, $0 \%$ very high). Beyond the 4.5 -year time point, the number at risk in the $A \beta$-positive groups declined substantially (figure 1). Consequently, progression was assessed at 4.5 years as well as for the full data set. At 4.5 years, carriage of $A P O E \varepsilon 4, H A$, and positive $A \beta$ scan were associated with significant increase in risk of clinical progression (table 3 ). Greatest risk was seen with high and very high $A \beta$ levels (HR 5.2 and 8.1, respectively). An uncertain or moderate $A \beta$ PET result did not affect the risk of clinical progression by 4.5 years (HR 1.3 and 0.9 , respectively). With the full data set, age greater than 72 years, low baseline memory performance on the CVLT-II LDFR, and moderate $\mathrm{A} \beta$ level (26-50 CL) emerged as significant risks. The risk from $A P O E \& 4$ carriage was unchanged, the risk from HA declined, and the risk from high and very high $\mathrm{A} \beta$ level increased (table 3 ). Figure 1 illustrates that progression to MCI or dementia in the moderate $A \beta$ level group occurred predominantly after 4.5 years of follow-up.

\section{$A \beta$ and Cognitive Change}

With sex, age, years of education, and APOE \&4 status as covariates, compared to the negative CL group, the moderate, high, and very high groups showed decline in longitudinal cognitive performance on the AIBL-PACC (moderate -0.02 $\mathrm{SD} /$ year, $p=0.05$; high $-0.08 \mathrm{SD} /$ year, $p<0.001$; and very high $-0.35 \mathrm{SD} /$ year, $p<0.001$ ) (figure 2 ). The same was observed for performance on the CVLT-II LDFR (moderate $-0.02 \mathrm{SD} /$ year, $p=0.03$; high $-0.1 \mathrm{SD} /$ year, $p<0.05$; and very high $-0.24, p<0.05)$. On the CDR-SoB, only the high and very high groups performed worse compared to the negative group (high $-0.17 / \mathrm{y}$ and very high $-0.38 / \mathrm{y}$ ). Practice effects were observed for the negative group on the AIBLPACC and CVLT-II LDFR (+0.18 SD/year and +0.04 SD/ year, respectively). No other significant differences were observed between the groups.

\section{Discussion}

In this study, we showed that the level of $\mathrm{A} \beta$ deposition in the brain could identify $\mathrm{CN}$ people at risk for cognitive decline and clinical progression to MCI or dementia and better stratify that risk than binary classification of an $\mathrm{A} \beta \mathrm{PET}$ scan as just positive or negative. The greatest cognitive decline and rate of clinical disease progression was seen in the participants with an $A \beta$ level higher than $50 \mathrm{CL}$. Participants with a moderately positive scan of 26-50 CL showed little clinical progression until after 4.5 years of follow-up. We found that the prevalence of MCI or dementia with an average follow-up of 5.3 years was $5 \%$ if $<15$ CL, 7\% if 16-25 CL, $12 \%$ if 26-50 CL, 28\% if 51-100 CL, and $50 \%$ if $>100 \mathrm{CL}$. This indicates that the level of $A \beta$ provides important prognostic information. 

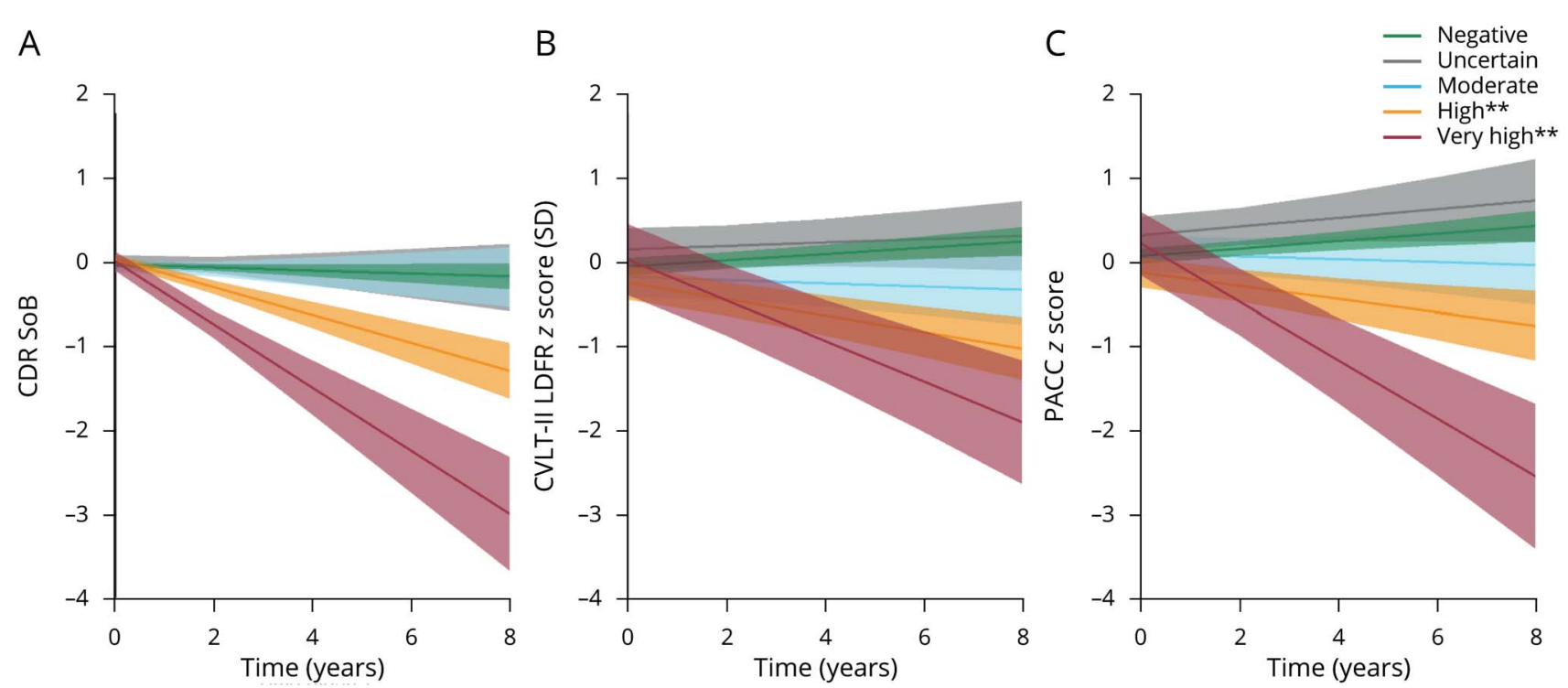

Cognitive trajectory measured by (A) Clinical Dementia Rating Sum of Boxes (CDR SoB), (B) California Verbal Learning Test II Long Delay Free Recall (CVLT-II LDFR), and (C) Preclinical AD Cognitive Composite (PACC). Shaded regions are $95 \%$ confidence interval. ${ }^{*} p<0.05$ and $* * * p<0.001$ significantly different slope from the "negative" reference category. Decline is against baseline for each category.

We have previously reported this observation but only in patients with ${ }^{11} \mathrm{C}$-PiB PET quantified with SUVR using inhouse-derived regions of interest. ${ }^{11}$ Consequently, the findings could not be easily translated into clinical practice. In the present larger study, we used the CL scale to allow inclusion of participants imaged with a variety of $\mathrm{A} \beta$ tracers $\left({ }^{11} \mathrm{C}-\mathrm{PiB}\right.$ in $44 \%,{ }^{18} \mathrm{~F}$-florbetapir in $27 \%,{ }^{18} \mathrm{~F}$-flutemetamol in $29 \%$ ) and to stratify the level of $A \beta$ into categories that can be replicated in any clinical or research PET site, purposes for which the CL method was developed. ${ }^{12}$

The close match of our cohort characteristics, including age, prevalence of $A P O E \varepsilon 4$, proportion with positive $A \beta P E T$, and clinical progression rate in the $A \beta$-positive participants, with other longitudinal studies of older $\mathrm{CN}$ cohorts suggests that our findings are widely applicable. ${ }^{27-31}$ For example, in our cohort, the risk of progression to MCI or dementia over a mean of 5.3 years of follow-up was $25 \%$ in $A \beta$-positive $\mathrm{CN}$ when defined as $>25 \mathrm{CL}$. This is consistent with progression rates for $\mathrm{A} \beta$-positive $\mathrm{CN}$ in the Mayo Clinic Study of Aging (18\% at 3.7 years), ${ }^{28}$ the Alzheimer's Disease Neuroimaging Initiative (ADNI) (32\% at 4 years), ${ }^{29}$ the Washington University Knight Alzheimer Disease Research Center (26\% at 5 years), ${ }^{30}$ and the Harvard Aging Brain Study (20\% at 3 years). ${ }^{31}$ Our study is unique in that it has demonstrated that the level of $A \beta$ deposition in a positive $A \beta$ scan provides additional prognostic information.

Our findings also have implications for preclinical AD therapeutic trials if slowing or halting cognitive decline is the proposed primary outcome measure. Suitable participants for such trials must be at high risk for detectable cognitive decline over the period of the study. Figure 2 suggests by separation of the confidence limits that the groups with high or very high $\mathrm{A} \beta$ burden (i.e., >50 CL) have significantly declined compared to the $A \beta$-negative group on several cognitive measures within 3 years of follow-up. In contrast, those with a moderate $A \beta$ burden declined much less compared to baseline performance, with minimal change and no increased risk of progression to MCI or dementia at 4.5 years (HR 0.9). This suggests that in a preclinical $\mathrm{AD}$ trial time frame of 3 to 4 years, therapeutic benefit may be better assessed in $\mathrm{CN}$ with $<50 \mathrm{CL}$ of $\mathrm{A} \beta$ by change in disease biomarkers rather than by slowing of cognitive decline.

In this study, we examined several measures known to be predictive of clinical progression in older $\mathrm{CN}$ adults. Low score on the baseline CVLT-II LDFR posed a moderate risk for clinical progression, though this may be a partly circular argument as low cognitive scores are a key component of a clinical diagnosis of MCI. As expected, APOE $\varepsilon 4$ carriage was associated with a 3-fold increase in risk of clinical progression. ${ }^{32,33}$ The effect of $\varepsilon 4$ may be indirect, as APOE $\varepsilon 4$ is associated with greater prevalence of $\mathrm{AD}$ and earlier disease onset so that at a given age, $\varepsilon 4$ carriers have more advanced disease and higher $A \beta$ levels. ${ }^{33}$ We found no effect of sex on progression risk. Other studies suggest that $\mathrm{AD}$ is more prevalent in women and females have a greater risk of clinical progression from MCI to $\mathrm{AD}$ dementia. ${ }^{34-36}$ More research is needed on the effect of sex differences in the preclinical phase of the development of $\mathrm{AD}$. HA predicts clinical progression to dementia and can discriminate patients with MCI from controls. ${ }^{37}$ In this study, the individuals with $\mathrm{HA}$ also had greater risk for progression. High and very high $A \beta$ level had the 
largest HRs for progression of any of the factors examined, reaching 8.1 in the very high group and 11.4 in the full data set. The very high $A \beta$ group had the highest prevalence of $H A$ and $A P O E \varepsilon 4$, both of which are consistent with longer disease duration and a more advanced preclinical stage of $\mathrm{AD}$ at the time of initial assessment.

We did not examine for interaction with other factors that may alter risk of disease progression in preclinical $\mathrm{AD}$. This includes comparison to the ATN (A $\beta$, tau, neurodegeneration) classification scheme ${ }^{7}$ as tau measures were not available at baseline in this cohort. Previous analysis of longitudinal data from AIBL reported that rate of decline on cognitive test scores in $\mathrm{CN}$ with positive $A \beta$ PET was greater in those who were APOE $\varepsilon 4$ carriers ${ }^{38}$ but this was not found in ADNI or BioFINDER ${ }^{27}$

Extrapolation of our findings to an individual should be approached with caution. A $\beta$ PET imaging of asymptomatic individuals other than for clinical trial screening is not recommended by the Society of Nuclear Medicine/Alzheimer's Association Amyloid Imaging Task Force. ${ }^{39}$ Although we have demonstrated that risk of clinically significant decline in $\mathrm{CN}$ older individuals is strongly related to the degree of $\mathrm{A} \beta$ burden, the value of this prognostic information remains unclear in the absence of effective treatment. Although the CL method provides a standardized measure of brain A $\beta$ burden, the results can differ slightly between laboratories due to factors such as PET camera make and model and local modifications to the standard CL method, some of which show tracer-dependent variance. ${ }^{14,25}$ Provided appropriate corrections have been made for modified methods, any residual variation between laboratories should not affect the conclusions of this study as they are based on groups with a broad range of CL. A limitation of all longitudinal studies is the withdrawal of participants over time. At 4.5 years, $15 \%$ of the stable cohort had withdrawn or not reached this time point. Their baseline demographics matched the entire cohort so this is unlikely to affect the study findings. The participant retention rate in this study compares well to other longitudinal studies. ${ }^{27}$

The level of $A \beta$ deposition is important for the prediction of progression to MCI or dementia. This study provides evidence that the currently used binary classification of positive or negative for the reporting of an $A \beta$ scan is suboptimal for determination of prognosis in $\mathrm{CN}$ older individuals. $\mathrm{A} \beta$ level stratified by CL-defined groupings provides greater individual prognostic information and should assist design of therapeutic trials in preclinical $\mathrm{AD}$.

\section{Acknowledgment}

The authors thank the participants who took part in the study as well as their families.

\section{Study Funding}

Core funding for the study was provided by the CSIRO Flagship Collaboration Fund and the Science and Industry
Endowment Fund in partnership with Austin Health, University of Melbourne, Edith Cowan University, Florey Institute of Neuroscience and Mental Health, Alzheimer's Australia, and the National Ageing Research Institute. The study also received funding from the National Health and Medical Research Council, the Dementia Collaborative Research Centres program, the McCusker Alzheimer's Research Foundation, and Operational Infrastructure Support from the Government of Victoria.

\section{Disclosure}

L. van der Kall and T. Truong report no disclosures. S.C. Burnham reports a patent, "Method for detection of a neurologic disease," issued to CSIRO. V. Doré, R.S. Mulligan, S. Bozinovski, and F. Lamb report no disclosures. P. Bourgeat reports a patent, "Method for detection of a neurologic disease," issued to CSIRO. J. Fripp reports a patent, "Method for detection of a neurologic disease," issued to CSIRO. S. Schultz, Y.Y. Lim, S.M. Laws, D. Ames, C. Fowler, S.R. Rainey-Smith, and R.N. Martins report no disclosures. O. Salvado reports a patent, "Method for detection of a neurologic disease," issued to CSIRO. J. Robertson reports no disclosures. P. Maruff is an employee of Cogstate Pty Ltd. C.L. Masters is a shareholder in Prana Biotechnology Ltd. V.L. Villemagne is supported by an NHMRC Senior Research Fellowship. C. Rowe is supported by an NHMRC Practitioner Fellowship (1140853) and has received research support from GE Healthcare, Avid Radiopharmaceuticals, and the National Health and Medical Research Council of Australia (1152623, 1132604, 1071430, 1011689). Go to Neurology. $\mathrm{org} / \mathrm{N}$ for full disclosures.

\section{Publication History}

Received by Neurology August 13, 2019. Accepted in final form September 24, 2020.

Appendix Authors

\begin{tabular}{|c|c|c|}
\hline Name & Location & Contributions \\
\hline $\begin{array}{l}\text { Laura M. } \\
\text { van der Kall, } \\
\text { MSc }\end{array}$ & $\begin{array}{l}\text { Austin Health, Melbourne, } \\
\text { Australia }\end{array}$ & $\begin{array}{l}\text { Designed and } \\
\text { conceptualized study, } \\
\text { analysed the data, drafted } \\
\text { the manuscript }\end{array}$ \\
\hline $\begin{array}{l}\text { Thanh } \\
\text { Truong, BH- } \\
\text { BMed }\end{array}$ & $\begin{array}{l}\text { Austin Health; University } \\
\text { of Melbourne, Australia }\end{array}$ & $\begin{array}{l}\text { Analysed the data, drafted } \\
\text { the manuscript, } \\
\text { interpretation of the data }\end{array}$ \\
\hline $\begin{array}{l}\text { Samantha C. } \\
\text { Burnham, } \\
\text { PhD }\end{array}$ & $\begin{array}{l}\text { CSIRO, Melbourne, } \\
\text { Australia }\end{array}$ & $\begin{array}{l}\text { Statistical design, } \\
\text { interpretation of the data, } \\
\text { revision of manuscript }\end{array}$ \\
\hline $\begin{array}{l}\text { Vincent } \\
\text { Doré, PhD }\end{array}$ & $\begin{array}{l}\text { CSIRO, Melbourne, } \\
\text { Australia }\end{array}$ & $\begin{array}{l}\text { Acquisition of the data, } \\
\text { interpretation of the data, } \\
\text { revision of manuscript }\end{array}$ \\
\hline $\begin{array}{l}\text { Rachel S. } \\
\text { Mulligan, } \\
\text { PhD }\end{array}$ & $\begin{array}{l}\text { Austin Health, Melbourne, } \\
\text { Australia }\end{array}$ & Data acquisition \\
\hline $\begin{array}{l}\text { Svetlana } \\
\text { Bozinovski, } \\
\text { RN }\end{array}$ & $\begin{array}{l}\text { Austin Health, Melbourne, } \\
\text { Australia }\end{array}$ & Administrative support \\
\hline
\end{tabular}


Appendix (continued)

\begin{tabular}{|c|c|c|}
\hline Name & Location & Contributions \\
\hline $\begin{array}{l}\text { Fiona Lamb, } \\
\text { DPsych }\end{array}$ & $\begin{array}{l}\text { Austin Health, Melbourne, } \\
\text { Australia }\end{array}$ & $\begin{array}{l}\text { Acquisition of data, } \\
\text { interpretation of data }\end{array}$ \\
\hline $\begin{array}{l}\text { Pierrick } \\
\text { Bourgeat, } \\
\text { PhD }\end{array}$ & CSIRO, Brisbane, Australia & $\begin{array}{l}\text { Acquisition of data, } \\
\text { interpretation of data, } \\
\text { revision of manuscript }\end{array}$ \\
\hline $\begin{array}{l}\text { Jurgen } \\
\text { Fripp, PhD }\end{array}$ & CSIRO, Brisbane, Australia & $\begin{array}{l}\text { Acquisition of data, } \\
\text { interpretation of data, } \\
\text { revision of manuscript }\end{array}$ \\
\hline $\begin{array}{l}\text { Stephanie } \\
\text { Schultz, MSc }\end{array}$ & $\begin{array}{l}\text { Washington University, St } \\
\text { Louis, MO }\end{array}$ & Interpretation of data \\
\hline $\begin{array}{l}\text { Yen Y. Lim, } \\
\text { PhD }\end{array}$ & $\begin{array}{l}\text { The Florey Institute of } \\
\text { Neuroscience and Mental } \\
\text { Health, Melbourne, } \\
\text { Australia }\end{array}$ & Acquisition of data \\
\hline $\begin{array}{l}\text { Simon M. } \\
\text { Laws, PhD }\end{array}$ & $\begin{array}{l}\text { Edith Cowan University, } \\
\text { Perth, Australia }\end{array}$ & $\begin{array}{l}\text { Acquisition of data, } \\
\text { interpretation of data, } \\
\text { revision of manuscript }\end{array}$ \\
\hline $\begin{array}{l}\text { David Ames, } \\
\text { MD }\end{array}$ & $\begin{array}{l}\text { University of Melbourne, } \\
\text { Australia }\end{array}$ & $\begin{array}{l}\text { Acquisition of data, } \\
\text { interpretation of data, } \\
\text { revision of manuscript }\end{array}$ \\
\hline $\begin{array}{l}\text { Christopher } \\
\text { Fowler, PhD }\end{array}$ & $\begin{array}{l}\text { The Florey Institute of } \\
\text { Neuroscience and Mental } \\
\text { Health, Melbourne, } \\
\text { Australia }\end{array}$ & Acquisition of data \\
\hline $\begin{array}{l}\text { Stephanie R. } \\
\text { Rainey- } \\
\text { Smith, PhD }\end{array}$ & $\begin{array}{l}\text { Edith Cowan University, } \\
\text { Perth, Australia }\end{array}$ & $\begin{array}{l}\text { Acquisition of data, } \\
\text { interpretation of data, } \\
\text { revision of manuscript }\end{array}$ \\
\hline $\begin{array}{l}\text { Ralph N. } \\
\text { Martins, } \\
\text { PhD }\end{array}$ & $\begin{array}{l}\text { Edith Cowan University, } \\
\text { Perth, Australia }\end{array}$ & $\begin{array}{l}\text { Interpretation of data, } \\
\text { revision of manuscript }\end{array}$ \\
\hline $\begin{array}{l}\text { Olivier } \\
\text { Salvado, } \\
\text { PhD }\end{array}$ & CSIRO, Brisbane & $\begin{array}{l}\text { Interpretation of data, } \\
\text { revision of manuscript }\end{array}$ \\
\hline $\begin{array}{l}\text { Joanne } \\
\text { Robertson, } \\
\text { DPsych }\end{array}$ & $\begin{array}{l}\text { The Florey Institute of } \\
\text { Neuroscience and Mental } \\
\text { Health, Melbourne, } \\
\text { Australia }\end{array}$ & Acquisition of data \\
\hline $\begin{array}{l}\text { Paul Maruff, } \\
\text { PhD }\end{array}$ & $\begin{array}{l}\text { The Florey Institute of } \\
\text { Neuroscience and Mental } \\
\text { Health, Melbourne, } \\
\text { Australia }\end{array}$ & $\begin{array}{l}\text { Acquisition of data, } \\
\text { interpretation of data, } \\
\text { revision of manuscript }\end{array}$ \\
\hline $\begin{array}{l}\text { Colin L. } \\
\text { Masters, MD }\end{array}$ & $\begin{array}{l}\text { University of Melbourne, } \\
\text { Australia }\end{array}$ & $\begin{array}{l}\text { Obtaining funding, } \\
\text { interpretation of data, } \\
\text { revision of manuscript }\end{array}$ \\
\hline $\begin{array}{l}\text { Victor L. } \\
\text { Villemagne, } \\
\text { MD }\end{array}$ & $\begin{array}{l}\text { Austin Health; University } \\
\text { of Melbourne, Australia }\end{array}$ & $\begin{array}{l}\text { Study concept and design, } \\
\text { acquisition of data, } \\
\text { interpretation of data, } \\
\text { revision of manuscript }\end{array}$ \\
\hline $\begin{array}{l}\text { Christopher } \\
\text { C. Rowe, MD }\end{array}$ & $\begin{array}{l}\text { Austin Health; University } \\
\text { of Melbourne, Australia }\end{array}$ & $\begin{array}{l}\text { Study concept and design, } \\
\text { acquisition of data, } \\
\text { interpretation of data, } \\
\text { drafting of manuscript }\end{array}$ \\
\hline
\end{tabular}

\section{References}

1. Jack CR Jr, Knopman DS, Jagust WJ, et al. Tracking pathophysiological processes in Alzheimers disease: an updated hypothetical model of dynamic biomarkers. Lancet Neurol 2013;12:207-216.

2. Villemagne VL, Burnham S, Bourgeat P, et al. Amyloid beta deposition, neurodegeneration, and cognitive decline in sporadic Alzheimer's disease: a prospective cohort study. Lancet Neurol 2013;12:357-367.
3. Budgeon CA, Murray K, Turlach BA, et al. Constructing longitudinal disease progression curves using sparse, short-term individual data with an application to Alzheimer's disease. Stat Med 2017;36:2720-2734.

4. Sperling RA, Aisen PS, Beckett LA, et al. Toward defining the preclinical stages of Alzheimer's disease: recommendations from the National Institute on AgingAlzheimers Association workgroups on diagnostic guidelines for Alzheimers disease. Alzheimers Demen 2011;7:280-292.

5. Chetelat G, Villemagne VL, Pike KE, et al. Independent contribution of temporal beta-amyloid deposition to memory decline in the pre-dementia phase of Alzheimer's disease. Brain 2011;134:798-807.

6. Ellis KA, Lim YY, Harrington K, et al. Decline in cognitive function over 18 months in healthy older adults with high amyloid-beta. J Alzheimers Dement 2013;34:861-871.

7. Jack CR Jr, Bennett DA, Blennow K, et al. NIA-AA Research Framework: toward a biological definition of Alzheimer's disease. Alzheimers Dement 2018;14:535-562.

8. Villemagne VL, Pike KE, Chetelat G, et al. Longitudinal assessment of Abeta and cognition in aging and Alzheimer disease. Ann Neurol 2011;69:181-192.

9. Doraiswamy PM, Sperling RA, Coleman RE, et al. Amyloid-beta assessed by florbetapir F 18 PET and 18-month cognitive decline: a multicenter study. Neurology 2012; 79:1636-1644.

10. Dang C, Harrington KD, Lim YY, et al. Relationship between amyloid-beta positivity and progression to mild cognitive impairment or dementia over 8 years in cognitively normal older adults. J Alzheimers Dis 2018;65:1313-1325.

11. Rowe CC, Bourgeat P, Ellis KA, et al. Predicting Alzheimer disease with beta-amyloid imaging: results from the Australian imaging, biomarkers, and lifestyle study of ageing. Ann Neurol 2013;74:905-913.

12. Klunk WE, Koeppe RA, Price JC, et al. The Centiloid project: standardizing quantitative amyloid plaque estimation by PET. Alzheimers Demen 2015;11: 1-15.e11-e14.

13. Rowe CC, Jones G, Dore V, et al. Standardized expression of 18F-NAV4694 and 11CPiB beta-amyloid PET results with the centiloid scale. J Nucl Med 2016;57: $1233-1237$.

14. Battle MR, Pillay LC, Lowe VJ, et al. Centiloid scaling for quantification of brain amyloid with [(18)F]flutemetamol using multiple processing methods. EJNMMI Res 2018;8:107.

15. Rowe CC, Dore V, Jones G, et al. ${ }^{18}$ F-Florbetaben PET beta-amyloid binding expressed in Centiloids. Eur J Nucl Med Mol Imaging 2017;44:2053-2059.

16. La Joie R, Ayakta N, Seeley WW, et al. Multisite study of the relationships between antemortem [11C]PIB-PET Centiloid values and postmortem measures of Alzheimer's disease neuropathology. Alzheimers Dement 2019;15:205-216.

17. Navitsky M, Joshi AD, Kennedy I, et al. Standardization of amyloid quantitation with florbetapir standardized uptake value ratios to the Centiloid scale. Alzheimers Dement 2018;14:1565-1571.

18. Dore V, Bullich S, Rowe CC, et al. Comparison of ${ }^{18} \mathrm{~F}$-florbetaben quantification results using MR-based and MR-less CapAIBL: validation against histopathology. Alzheimers Dement 2019;15:807-816.

19. Amadoru S, Dore V, McLean CA, et al. Comparison of amyloid PET measured in Centiloid units with neuropathological findings in Alzheimer's disease. Alzheimer Res Ther 2020;12:22.

20. Ellis KA, Bush AI, Darby D, et al. The Australian Imaging, Biomarkers and Lifestyle (AIBL) study of aging: methodology and baseline characteristics of 1112 individuals recruited for a longitudinal study of Alzheimer's disease. Int Pyschogeriatr 2009;21: 672-687.

21. Winblad B, Palmer K, Kivipelto M, et al. Mild cognitive impairment-beyond controversies, towards a consensus: report of the international working group on mild cognitive impairment. J Intern Med 2004;256:240-246.

22. McKhann G, Drachman D, Folstein M, Katzman R, Price D, Stadlan EM. Clinical diagnosis of Alzheimer's disease: report of the NINCDS-ADRDA Work Group under the auspices of Department of Health and Human Services Task Force on Alzheimer's Disease. Neurology 1984;34:939-944.

23. Donohue MC, Sperling RA, Salmon DP, et al. The preclinical Alzheimer cognitive composite: measuring amyloid-related decline. JAMA Neurol 2014;71:961-970.

24. Bourgeat P, Villemagne VL, Dore V, et al. Comparison of MR-less PiB SUVR quantification methods. Neurobiol Aging 2015;36:S159-S166.

25. Bourgeat $\mathrm{P}$, Dore V, Fripp J, et al. Implementing the centiloid transformation for ${ }^{11} \mathrm{C}$ $\mathrm{PiB}$ and $\beta$-amyloid ${ }^{18} \mathrm{~F}$ PET tracers using CapAIBL. Neuroimage 2018;183:387-393.

26. Bourgeat P, Dore V, Shen K, Raniga P, Salvado O, Fripp J. Enforcing Longitudinal Consistency in Longitudinal analysis using multi-atlas segmentation. Presented at: MICCAI 2012 Workshop on Novel Imaging Biomarkers for Alzheimer's Disease and Related Disorders, Nice, France, October 5, 2012.

27. Insel PS, Weiner M, Mackin RS, et al. Determining clinically meaningful decline in preclinical Alzheimer's disease. Neurology 2019;93:e322-e333.

28. Roberts RO, Aakre JA, Kremers WK, et al. Prevalence and outcomes of amyloid positivity among persons without dementia in a longitudinal, population-based setting. JAMA Neurol 2018;75:970-979.

29. Donohue MC, Sperling RA, Petersen R, et al. Association between elevated brain amyloid and subsequent cognitive decline among cognitively normal persons. JAMA 2017;317:2305

30. Hassenstab J, Chasse R, Grabow P, et al. Certified normal: Alzheimer's disease biomarkers and normative estimates of cognitive functioning. Neurobiol Aging 2016;43: 23-33.

31. Papp KV, Buckley R, Mormino E, et al. Clinical meaningfulness of subtle cognitive decline in longitudinal testing in preclinical AD. Alzheimers Dement 2020;16: $552-560$. 
32. Fleisher AS, Sowell BB, Taylor C, et al. Clinical predictors of progression to Alzheimer disease in amnestic mild cognitive impairment. Neurology 2007;68:1588-1595.

33. Hollands S, Lim YY, Laws SM, et al. APOE-epsilon4 genotype, amyloid, and clinical disease progression in cognitively normal older adults. J Alzheimers Dis 2017;57: 411-422.

34. Prince M, Ali GC, Guerchet M, Prina AM, Albanese E, Wu YT. Recent global trends in the prevalence and incidence of dementia, and survival with dementia. Alzheimers Res Ther 2016;8:23.

35. Lin KA, Choudhury KR, Rathakrishnan BG, et al. Marked gender differences in progression of mild cognitive impairment over 8 years. Alzheimers Dement 2015;1: $103-110$.
36. Gao S, Hendrie HC, Hall KS, Hui S. The relationships between age, sex, and the incidence of dementia and Alzheimer disease: a meta-analysis. Arch Gen Psychiatry 1998;55:809-815.

37. Henneman WJP, Sluimer JD, Barnes J, et al. Hippocampal atrophy rates in Alzheimer disease: added value over whole brain volume measures. Neurology 2009;72:999-1007.

38. Lim YY, Kalinowski P, Pietrzak RH, et al. Association of $\beta$-Amyloid and apolipoprotein $\mathrm{E}$ e4 with memory decline in preclinical Alzheimer disease. JAMA Neurol 2018;75:488-494.

39. Johnson KA, Minoshima S, Bohnen NI, et al. Appropriate use criteria for amyloid PET: a report of the Amyloid Imaging Task Force, the Society of Nuclear Medicine and Molecular Imaging, and the Alzheimer's Association. Alzheimers Dement 2013;9:e1-e16. 


\section{Neurology}

\section{Association of $\beta$-Amyloid Level, Clinical Progression, and Longitudinal Cognitive Change in Normal Older Individuals \\ Laura M. van der Kall, Thanh Truong, Samantha C. Burnham, et al. \\ Neurology 2021;96;e662-e670 Published Online before print November 12, 2020}

DOI 10.1212/WNL.0000000000011222

This information is current as of November 12, 2020

Updated Information \& Services

References

Citations

Subspecialty Collections

Permissions \& Licensing

Reprints including high resolution figures, can be found at: http://n.neurology.org/content/96/5/e662.full

This article cites 38 articles, 6 of which you can access for free at: http://n.neurology.org/content/96/5/e662.full\#ref-list-1

This article has been cited by 2 HighWire-hosted articles: http://n.neurology.org/content/96/5/e662.full\#\#otherarticles

This article, along with others on similar topics, appears in the following collection(s):

Alzheimer's disease

http://n.neurology.org/cgi/collection/alzheimers_disease

Cognitive aging

http://n.neurology.org/cgi/collection/cognitive_aging

MCI (mild cognitive impairment)

http://n.neurology.org/cgi/collection/mci_mild_cognitive_impairment PET

http://n.neurology.org/cgi/collection/pet

Prognosis

http://n.neurology.org/cgi/collection/prognosis

Information about reproducing this article in parts (figures,tables) or in its entirety can be found online at:

http://www.neurology.org/about/about_the_journal\#permissions

Information about ordering reprints can be found online:

http://n.neurology.org/subscribers/advertise

Neurology ${ }^{\circledR}$ is the official journal of the American Academy of Neurology. Published continuously since 1951, it is now a weekly with 48 issues per year. Copyright Copyright ( 2020 The Author(s). Published by Wolters Kluwer Health, Inc. on behalf of the American Academy of Neurology.. All rights reserved. Print ISSN: 0028-3878. Online ISSN: 1526-632X.

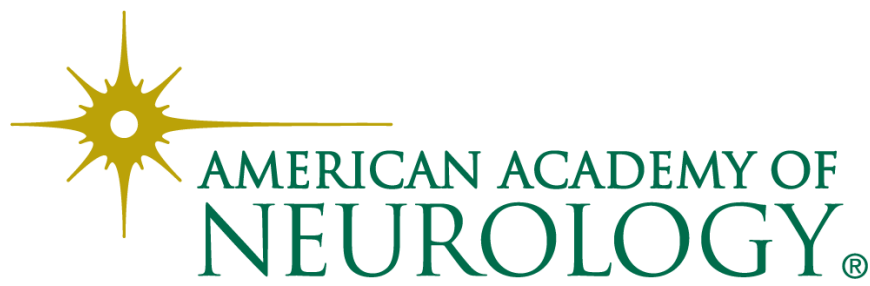

